\title{
An Analysis of the Types and Factors of Parents' Language Awareness in the Chinese-Arab Families
}

\author{
Hanze Guan ${ }^{1, *}, \dagger$ Xin Lv $^{2, \dagger}$ Junjie Wang ${ }^{3, \dagger}$ Qiyuan Wang ${ }^{4, \dagger}$
}

\author{
${ }^{1}$ Sun Yat-sen University, Zhuhai, Guangdong, China \\ ${ }^{2}$ Liaoning University, Shenyang, Liaoning, China \\ ${ }^{3}$ Southwestern University of Finance and Economics, Chengdu, Sichuan, China \\ ${ }^{4}$ No. 1 Middle School Jiangsu Province, Suzhou, Jiangsu, China \\ ${ }^{*}$ Corresponding author.Email: ${ }^{1}$ guanhz@mail2.sysu.edu.cn \\ ${ }^{t}$ Those authors contributed equally.
}

\begin{abstract}
Parents' language awareness is an important part of language policy, which virtually affects children's language acquisition. A variety of parents' awareness appears in different families under the impact of various micro and macro factors. Parents' language beliefs and their language attitudes are analyzed through the investigation of parents' language awareness. In this way, the inheritance and development of language in the next generation will be revealed. According to interviews with Chinese-Arab families, this research divides parents' language awareness into three types: positive, neutral and negative, and summarizes factors. Moreover, the combination of interracial families reveals the exchange and integration of civilizations to a great extent, which involves the inheritance and development of family inheritance languages in a non-native area. The study of inter-ethnic Chinese-Arab families is more conducive to the analysis of cultural integration and conflict in the communication with Chinese and Arab nations.
\end{abstract}

Keywords: parents' language awareness, family language planning, mixed Chinese Arab families.

\section{INTRODUCTION}

\subsection{Background}

In recent years, since the Belt and Road Initiative, a large number of Arabs have come to China to invest and formed China-Arab families. Therefore, the language acquisition of children from this interracial bilingual family has attracted wide attention from linguists. They believe that the family environment is considered to be the main place where children acquire language. For children aged $0-3$, the home language environment is largely considered the only place for language acquisition. Parents' awareness to children's language learning directly affects their language learning and use. Hence, the study on the types and influencing factors of language awareness of parents in Chinese-Arab families are helpful to the research of language acquisition of children in this family.

\subsection{Literature Review}

King said that language awareness, that is, language users know what language can be used for and how to use language [1], which originated from the "language Awareness Movement" launched by language education circle in British in the 1980s. By this movement, numerous linguists and language educators hope to improve the quality of language learning by improving students' language awareness. Hence, scholars such as Spolsky, Silverstein, King, Pakir have tried to use "language awareness" to explain some phenomena in language acquisition. In this context, the Language Awareness Association was founded in October 1991, following a special seminar on Language Awareness held in London. "Language Awareness" (quarterly) was published by the Language Awareness Association in the same year. Because of this, the research and teaching of language awareness soon gained wide attention in teacher training, language teaching and research and other fields. In such an environment, Spolsky has studied language awareness for many years. He pointed out that language awareness is a part of language policy 
that also includes language management and language practice [2]. Besides King thought that language policy is applicable to the state, society, government, religious organizations, schools, families and other small units [3]. In this context, some scholars applied this theory to the family field, studied the problems related to the inheritance of language and developed the theory of family language planning. According to the family language planning theory, Pakir proposed the invisible language planning, which is a kind of non-government language planning spontaneously generated for the acquisition and use of a certain language [4]. Following this research direction, linguists have begun to study the relationship between children's language acquisition and parents' language awareness. For example, Seloni \& Sarfati found that parents from Spanish-Turkish families do not support their children learning Turkish because they think there is a conflict between the dominant language learning and the learning of Turkish [5]. Moreover, some studies have found that parents' language awareness conflicts with their actual language choices. For example, Chatzidaki \& Maligk-Oudi found that although Greek-Albanian parents recognized Albanian as their native language, they did not take active measures to encourage their children to learn Albanian, but regarded Greek as their top priority [6]. In addition, Wang Ling \& Zhi Xiaoshi concluded that there are differences in language awareness among Chinese parents living in the United States [7]. Furthermore, some studies also examined the major factors to parents' language awareness, such as parents' language ability, education level, parents' own social experience, Parents' identities, multilingual education policy in schools.

King believed that even within the same ethnic group, the language awareness of parents also varies [8] and Silverstein thought language awareness can be divided into different types [9]. For different ethnic groups, the cultural environment is different, which leads to the diversity of parents' language awareness in cross-ethnic families. Therefore, we can explore the types of parents' language awareness and classify them simply by examining their attitudes towards language and beliefs. We find that previous researchers have mostly chosen overseas immigrant families as respondents, while few researchers have explored families with their children equipped with bilingual. Moreover, there are few studies on Chinese-Arab bilingual families. On the basis of these, the types of parents' language awareness in such families deserve further study.

Although Arabic is one of the six common languages of the United Nations, few scholars in China have discussed parents' attitudes towards the differences between Chinese and Arabic and the factors influencing children's learning of these two languages. Therefore, the current study intends to conduct the study in this paper study the causes of parents' language awareness in Chinese-Arab families, so as to analyze which factors play a more critical role in the formation of parents' language awareness.

\subsection{Methodology}

The survey was conducted among Chinese and Arab families in Yiwu, China, and Dubai, UNITED Arab Emirates. 24 families participated in this recorded interview and we tried our best to speak with both the mother and father. Parents are free to talk in either of the two languages (Chinese and Arab), and they usually choose their native language to communicate with interviewers. Besides, 24 families were recruited through announcements on a social network and handouts. Interviewers had a cooperation with a well-known educational institution in China and were allowed to post announcements of recorded interviews on its accounts on social network. In order to attract more parents, they were offered a free 10-hour course at the institute. Interviewers also asked some questions to the parents of the two Turban international kindergartens in the form of questionnaire to determine if they have qualifications of interview. Eligible families had at least one child under the age of eight and parents raised their children in Chinese or Arabic.

All the interviews had the nearly same questions. At the beginning of the it, parents with the positive attitude were asked about their background information, such as income, age, education level, occupation, living time in this area. They also talked about their views on the two cultures (Chinese and Arabic). On the basis of it, they were interviewed with questions like "would you teach your children learn Chinese and Arabic?" and "why would you teach your children learn or give up Chinese or Arabic?"

All interviews were ended with talking to parents about their children's language development goals and ways they can support their kids' language learning. Interviewers tried to cut into the conversation as much as possible from various angles and issues that parents were more interested in. Most of these interviews took place in living rooms or kitchens of parents in relaxed and comfortable atmospheres.

\section{CASE ANALYSIS}

In this chapter, our interviews and analysis will be presented according to the theories from the previous chapter. According to the interview content, the language awareness of Chinese-Arab parents can be classified into following three types. But before discussing the awareness of the three languages, we need to summarize the macro situation of the interviewers we selected and compile them into the following table. 
Table 1. Interviewee's family profile

\begin{tabular}{|c|c|c|}
\hline \multirow[t]{2}{*}{ Main interviewees } & $\begin{array}{l}\text { Father } \\
\text { Mother }\end{array}$ & $\begin{array}{l}6 \text { families } / 30 \% \\
14 \text { families/70\% }\end{array}$ \\
\hline & $\begin{array}{l}\text { Under } 30 \text { (include } \\
30 \text { ) }\end{array}$ & 15 people/37.5\% \\
\hline \multirow{4}{*}{ Parental age } & $31-39$ & 10 people/25\% \\
\hline & $\begin{array}{l}\text { Over } 40 \\
40)\end{array}$ & 5 people $/ 12.5 \%$ \\
\hline & Unknown & 10 people/25\% \\
\hline & $\begin{array}{l}\text { Bachelor degree or } \\
\text { below }\end{array}$ & 11 people/27.5\% \\
\hline \multirow{2}{*}{$\begin{array}{l}\text { Educational } \\
\text { background }\end{array}$} & $\begin{array}{l}\text { Master degree } \\
\text { Doctoral degree } \\
\text { Unknown }\end{array}$ & $\begin{array}{l}17 \text { people/42.5\% } \\
5 \text { people/ } 12.5 \% \\
7 \text { people/ } 17.5 \%\end{array}$ \\
\hline & $\begin{array}{l}\text { Company } \\
\text { category }\end{array}$ & 13 people/32.5\% \\
\hline \multirow{2}{*}{$\begin{array}{l}\text { Working } \\
\text { background }\end{array}$} & $\begin{array}{l}\text { Teacher, Doctor, } \\
\text { Lawyer... }\end{array}$ & 8 people/20\% \\
\hline & $\begin{array}{l}\text { Businessman } \\
\text { Other } \\
\text { Unknown }\end{array}$ & $\begin{array}{l}8 \text { people } / 20 \% \\
8 \text { people } / 20 \% \\
3 \text { people } / 7.5 \%\end{array}$ \\
\hline
\end{tabular}

The table shows that most of the interviewees are mothers. Moreover, most of them are under the age of 40 , with relatively high education level and stable and decent work. Such groups are consistent in many aspects, which is convenient for unified analysis of data.

\subsection{Positive parents' language awareness}

It means that parents have a positive attitude towards their children's learning of Chinese or Arabic. They can actively support their children's acquisition of bilingualism, and support their children's choice of languages, and believe their own language behavior can influence their children's acquisition of a certain language.

(1) Chinese is the cultural treasure of the Chinese nation, while Arabic is the religious language of the Islamic world. Language is the key of cultural heritage

Sample 1:

Mother, 30, Chinese, master, clerk of a commercial company, has been to Dubai for nearly 3 years, not proficient in Arabic.

Father, 35, Arab in Dubai, master, engineer.

"Languages are important, and we hope our baby could learn more languages. Our two regions have a long history of culture in the world respectively. Moreover, our family believe in Islam and read the Koran every day during worship, so the children had to learn Arabic. From my view, our baby could have a better understanding capacity of the two different cultures with bilingualism."

\section{(2) Bilingualism do help to a child's future development}

Sample 20:
Mother, 29, Chinese, master, is not able to speak Arabic.

Father, 34, Arabic, master, merchant, has been to Yiwu for more than 5 years, not proficient in Chinese.

"The trade between China and Arab countries is getting closer and closer, while my husband often goes back and forth between Dubai and Yiwu. He lets our children learn his language, maybe because he hopes our son could inherit his business in the future. Knowing more than one language makes him competitive".

\section{(3) Language can promote emotional communication between family members}

Sample 15:

Mother, 27, master, Chinese teacher, is not able to speak Arabic and has been living in China for 23 years.

Father, 33, master, merchant, can speak a little of Chinese and has been living in China for 7 years.

"(Father)My wife and I usually communicate with each other in Chinese and English. (Mother) I feel a little sorry that I can't speak Arabic, so I can't communicate with my husband's family members in Arabic. I hope my children can communicate with relatives in Arabic and Chinese."

\section{(4) The community has a strong foreign} language learning atmosphere

\section{Sample 17:}

Mother, 27, master, hospital nurse, Dubai's Chinese.

Father, 28, master, merchant, Arab.

"(Mother) I grew up here in Chinatown. Even though I married the local, the community we live in insists on teaching Chinese to our children, so I speak Chinese to my children."

The interviews show that positive language awareness is influenced by national policies, family structure, national ideology, parents' work and education. These factors can be initially divided into macro and micro types.

At the macro level, language is a basic tool for communication between different nationalities. In recent decades, the cooperation between China and Arab countries has become increasingly close. The socio-economic development driven by economic cooperation has enhanced the bilateral influence of Chinese and Arabic languages. The preference of national policy has made this group of parents with a certain international perspective deeply aware of the importance of Chinese and Arabic, that is, bilingualism is good for their children's future development. 
At the micro level, first of all, parents have a clear understanding of the importance of their mother tongue culture and strong beliefs, so they insist to let their children learn two languages. To some extent, that depends on the educational factors and national identity of parents. Secondly, the need for emotional communication in the family is also one of the important factors affecting language learning. Some groups of parents have realized that Chinese and Arabic both are the basic tools for communication among family members, and their learning is highly irreplaceable. In addition, the educational atmosphere of the community where the family lives will also affect the parents' attitudes towards the two languages. For example, the mother in interview sample 17 was born in Dubai, but she also actively promotes her children to learn Chinese because people around her teach them Chinese.

\subsection{Neutral parents' language awareness}

This kind of parents have a certain understanding of the importance of Chinese and Arabic but weak beliefs. But for some certain reasons, they take casual attitudes towards helping and creating conditions for their children to learn Chinese and Arabic.

\section{(5) Less time for family life due to the busy work}

Sample 11:

Mother, about 42, doctor, associate professor in a university of Dubai, Chinese, fluent in Arabic, has lived in Dubai for more than 10 years.

Father, 39, education (unknown), merchant, native of Dubai, speaks basic Chinese and has lived in Dubai for 39 years

"(Mother) We have three kids. When the first two were born, I just came to Dubai and my work was not so busy that I could always use Chinese to communicate with my children. Sometimes my husband also used Chinese to communicate with my children, so we had more time to spend with our children and our first and second children are able to speak Chinese. After the third child was born, my work in the university became busier. My husband could not accompany the child at that time due to business. As a result, the third child could hardly speak Chinese....... We just didn't have enough time or energy to teach them Chinese, so we gradually lost focus."

Such parents consciously teach their children to speak Chinese, but they do not create good conditions and environment for their children to learn Chinese, nor do they actively support them. Because of their busy work, they did not pay attention to their children's language learning, even though the parent knew that they played an important role in their children's learning. This also shows that there is not a good environment for learning Chinese in Dubai, which also affects the couple's enthusiasm to teach their children Chinese. Based on this, we can say that the formation of neutral parents' language awareness is mainly influenced by their parents' work, which makes them have no time and energy to pay attention to their acquisition of children. At the macro level, there are not many occasions to learn Chinese in Dubai at present. And all of these factors lead to such awareness.

\section{(6) The unbalanced importance of different} languages in a region

Sample 9:

Mother, 36, master, clerk of a company, Chinese, is able to speak a little of Arabic.

Father, 49, master, trader, Arab, is able to speak some Chinese and has resided in China for more than 5 years.

The father said that Arabic is significant to learn, but I don't have time to take care of my child or just help him learn Arabic. Her mother spoke a little bit of Arabic, but she can't teach my daughter.

The mother said although learning more languages do help to the future development of the children, but there are few opportunities to use Arabic in China, so I don't think it is necessary to ask my children to learn Arabic.

From the interview, it can be seen that such parents are aware of the importance of learning a foreign language. But generally due to the conflict between work and family life, parents can't create a foreign language learning environment for their children to learn. They just take a natural approach to bilingualism.

\section{(7) Neglect of the importance in language learning}

Sample 22:

Father, 55, doctor, manager of a company, age (unknown), Chinese, fluent in Arabic, lived in Dubai for 25 years.

Mother, 30, master, housewife, age(unknown), native and is incapable of Chinese.

"(Father)My wife and I are very supportive of our children's Chinese learning, but now in Dubai schools emphasize not only the importance of learning but also physical fitness. My son is young and he wants to learn equestrian and tennis. These two sports have occupied most of his time. When he comes back home, I usually communicate with him in Chinese and teach him learn 
Chinese. But if he is not too interested, I use Arabic. In general, he is not forced to learn Chinese."

These parents support their children in learning Chinese and also communicate with them in Chinese. However, they are not force their children to learn Chinese. Parents in such families choose whether to teach their children Chinese or not according to their children's interest. If the children are interested in learning, they communicate in Chinese, and if the children are not interested, they use Arabic that the children are familiar with. Parents do not try to take special measures to help their children learn Chinese. In conclusion, such parents have a neutral sense of language.

\subsection{Negative parents' language awareness}

These parents are not aware of the importance of learning Chinese or Arabic, and do not understand the significant role of these two languages, so they have a negative attitude and no belief. They do not support or create conditions for their children to learn Chinese or Arabic.

\section{Sample 5:}

Mother, 43, master, clerk of a company, Chinese, fluent in Arabic, has been in Dubai for over 20 years.

Father, 55 years old, master, merchant, native of Dubai, does not speak Chinese and has lived in Dubai all his life.

"I've been married here for more than 20 years and converted to Islam, mother said. "I think it is better for my child to develop in Dubai in the future, and the welfare benefits are much better than those in China. It's hard for him to go back to China anyway, so I won't teach him Chinese. I want him to spend more time doing what he wants."

Because of religious issues, these parents are more likely to recognize the identity of Dubai (the children's living country) and its status. They think Arabic is more conducive to their children's future development, thus they deny the function of Chinese in Arab countries. This is the result of the influence of social and cultural background at the macro level. The fact that Chinese does not have a powerful advantage in Dubai has influenced these parents to deny the value of Chinese.

Sample 16:

Father, age(unknown), doctor, university professor, can only use Chinese in a daily conversation, has lived in China for 2 years.

Mother, age(unknown), undergraduate, housewife, fluent in Arabic.

"We sent our son to private school to learn Arabic when he was very young, but within a few months he was very resistant. I began to discuss with my husband not to let him learn Arabic, my husband refused firstly. Then we had a few fights because of the problem of Arabic learning, which led to bad family atmosphere. we stopped teaching our child Arabic."

\section{Sample 12:}

Mother, 30, education (unknown), housewife, speaks basic Arabic and has lived in Dubai for 9 years.

"When our baby was born, my husband and I asked many friends about some education problems. Our neighbors told us that it is not good for children to learn many languages, which will affect their future language learning."

Influenced by the unscientific viewpoint of special education, the Chinese mother in the interview held a negative attitude towards their children's Chinese learning and did not have any supportive behaviors. The formation of such language awareness is influenced by parents' own factors, and is closely related to parents' own understanding of multilingualism and external interference.

\section{CONCLUSION}

Based on the theory of De Houwer, parents' language awareness can be specifically investigated [10]. This research introduces the concept of parents' language awareness in a new family perspective. Through the interviews with the interracial families, the classification of parents' language awareness concluded by the predecessors and its feasibility have been proved to some extent. By classifying parents' attitudes towards their children's language learning, parents' language awareness in the Chinese-Arab families can be divided into three categories: positive, vague and negative.

Parents with positive language awareness fall into two categories. One kind of parents will actively guide their children to learn two inherited languages. This kind of parents will create a good language learning environment for their children. And they will deliberately create another inherited language environment for their children in the home country where the language is opposite, and hope their children can skillfully use both languages. The other is affected by language belief, and they also hope their children can master their inherited language, but they cannot participate in the learning process of their children's inherited language due to work or other reasons. These parents have strong language belief and positive language attitude, but they cannot reflect their children's language learning.

Parents with neutral language awareness have a common tendency to neglect the education of their offspring. Due to personal and work reasons, such parents lack of participation in family life, and they 
usually adopt a laissez-faire attitude to their children's language education and let it develop.

Most parents with negative language awareness think that it is meaningless to require their children to learn two inherited languages deliberately, and generally believe that it is enough for children to learn the language used in the home country. They would prefer their children to devote their energy to other things.

These three types of parents' language awareness are influenced by personal, social, religious and other factors, which are simply classified and given names in this paper. Parents with positive language awareness, some because of the confidence of national culture, some because of the need for religious traditions, and some have a vision of their children's development.

By summarizing the interview data, the above conclusion is well supported. Parents' language awareness has a substantial impact on children, showing an obvious correlation. If parents have positive language awareness, children can skillfully use at least one language and understand and use another language to a certain extent. If parents have negative language awareness, children can hardly understand another language. The details are shown in the table below.

Table 2 Family residence and children's language ability

\begin{tabular}{|c|c|c|c|c|}
\hline Serial number & $\begin{array}{ll}\begin{array}{l}\text { Parents } \\
\text { awareness }\end{array} & \text { language } \\
\end{array}$ & Location & $\begin{array}{ll}\text { Chinese } & \text { language } \\
\text { proficiency } & \\
\end{array}$ & $\begin{array}{ll}\text { Arabic } & \text { language } \\
\text { proficiency } & \\
\end{array}$ \\
\hline 1 & Positive & Dubai, UAE & Enough for daily use & Enough for daily use \\
\hline 2 & Ambiguous & Dubai, UAE & $\begin{array}{l}\text { Can understand difficult to } \\
\text { use }\end{array}$ & Enough for daily use \\
\hline 3 & Positive & Dubai, UAE & Enough for daily use & Enough for daily use \\
\hline 4 & Ambiguous & Abu Dhabi, UAE & $\begin{array}{l}\text { Can understand difficult to } \\
\text { use }\end{array}$ & Enough for daily use \\
\hline 5 & Negative & Dubai, UAE & Completely can't use & Enough for daily use \\
\hline 6 & Positive & Dubai, UAE & Enough for daily use & Enough for daily use \\
\hline 7 & Ambiguous & Dubai, UAE & Enough for daily use & Completely can't use \\
\hline 8 & Positive & Dubai, UAE & Enough for daily use & $\begin{array}{l}\text { Can understand difficult to } \\
\text { use }\end{array}$ \\
\hline 9 & Ambiguous & Yiwu, China & Enough for daily use & $\begin{array}{l}\text { Can understand difficult to } \\
\text { use }\end{array}$ \\
\hline 10 & Positive & Abu Dhabi, UAE & Enough for daily use & Enough for daily use \\
\hline 11 & Ambiguous & Dubai, UAE & $\begin{array}{l}\text { Can understand difficult to } \\
\text { use }\end{array}$ & Enough for daily use \\
\hline 12 & Negative & Dubai, UAE & Completely can't use & Enough for daily use \\
\hline 13 & Ambiguous & Abu Dhabi, UAE & $\begin{array}{l}\text { Can understand difficult to } \\
\text { use }\end{array}$ & Enough for daily use \\
\hline 14 & Positive & Yiwu, China & Enough for daily use & Enough for daily use \\
\hline 15 & Positive & Yiwu, China & Enough for daily use & $\begin{array}{l}\text { Can understand difficult to } \\
\text { use }\end{array}$ \\
\hline 16 & Negative & Yiwu, China & Enough for daily use & Completely can't use \\
\hline 17 & Positive & Dubai, UAE & Enough for daily use & Enough for daily use \\
\hline 18 & Positive & Abu Dhabi, UAE & Enough for daily use & Enough for daily use \\
\hline 19 & Negative & Dubai, UAE & Completely can't use & Enough for daily use \\
\hline 20 & Positive & Yiwu, China & Enough for daily use & $\begin{array}{l}\text { Can understand difficult to } \\
\text { use }\end{array}$ \\
\hline
\end{tabular}

On the world stage, the Chinese-Arab families have certain particularities. Chinese and Arabic represent two ancient civilizations and two important ideologies in the international political arena. In this study, it can be found that the classification of parents' language awareness in Chinese-Arab families reflects the essence of language communication, that is, the cultural integration and collision between the two sides of language communication. Culture directly affects the language beliefs of both parents, and the intensity of language beliefs decreases layer by layer under positive, vague and negative language awareness. According to statistics, the proportion of positive parents' language awareness types in the Chinese-Arab families is generally superior, which can be considered to be related to cultural factors. Based on this point, the secondary elaboration of the language consciousness types of parents in Chinese-Arab families and the in-depth study of the reasons behind them will contribute to the further study of the conflict and integration between Islam and the ideology of Chinese civilization, so as to play a guiding and demonstration role in the linguistically oriented intercultural interactive communication.

Language environment is an important factor in the development of children's language ability, so the acquisition of inherited language in a country other than the family's home country becomes an important yardstick to evaluate the influence of language awareness on children's inherited language acquisition. With the transition of parents' language attitude from positive to negative, children's language ability also decreases. Through interviews on children's language ability in different families, the positive correlation between language ability and parents' language awareness was clearly found. Children in families with vague parents' awareness of language tend to lag behind their native speakers in their non-native language. In the interview process, it is found that some children living in families with vague parents' language awareness have weak writing ability in the language of their non-living place, and they also make more or less grammatical 
mistakes in the process of expression, and their language expression is heavily influenced by the language of their living place.

\section{REFERENCES}

[1] Kendall, A. King, Lyn Fogle, Aubrey Logan- Terry, Family language policy, in: Language and Linguistics Compass (5): 907-922, 2008

[2] B. Spolsky, Language Policy. Cambridge, in: Cambridge University Press, 2004

[3] Kendall, A. King, Lyn Fogle, Bilingual parenting as good parenting: Parents' perspectives on family language policy for additive bilingualism., in: International Journal of Bilingual Education and Bilingualism (6), 2006

[4] A. Pakir, Education and invisible language planning: The case of English in Singapore, in T. Kandiah \& K. Kwan-Terry (Eds.), English Language Planning: A Southeast Asian Contribution. Singapore: Centre for Advanced Studies and Times Academic Press, 1994

[5] Lisya Seloni, Yusuf Sarfati, (Trans)national language ideologies and family language practices: A life history inquiry of Judeo- Spanish in Turkey, in: Language Policy (1), 2013

[6] Chatzidaki, Maligkoudi, Family language policies among Albanian immigrants in Greece (6), 675-689, 2013

[7] Ling Wang, Xiao Shi Zhi, An Analysis of the Types and Influencing Factors of Chinese American Parents' Language Ideology, in: TCSOL Studies, 2020

[8] Kendall, A. King, Language ideologies and heritage language education, in: International Journal of Bilingual Education and Bilingualism (3): $167-184,2000$

[9] M. Silverstein, Language structure and linguistic ideology, in: R. Clyne, W. Hanks \& C. Hofbauer (Eds.), The Elements: A Parasession on Linguistic Units and Levels. Chicago: Chicago Linguistic Society, 1979

[10] A. De Houwer, Environmental factors in early bilingual development: The role of parental beliefs and attitudes, in: G. Extra \& L. Verhoeven (Eds.), Bilingualism and Migration. Berlin: Mouton de Gruyter, 1999 